\title{
Cocoa butter substitute (CBS) produced from palm mid-fraction/palm kernel oil/palm stearin for confectionery fillings
}

\begin{abstract}
This study investigated the physicochemical properties of ternary mixtures of palm midfraction (PMF):refined bleached deodorized palm kernel oil (RBDPKO):refined bleached deodorized palm stearin (RBDPS) for cocoa butter substitute (CBS). Fatty acid constituents, triacylglycerol constituents, solid fat contents (SFCs), melting behavior, polymorphism and crystal morphology were determined using gas chromatography (GC), high-performance liquid chromatography (HPLC), differential scanning calorimetry (DSC), pulsed nuclear magnetic resonance ( $\mathrm{p}$-NMR), X-ray diffraction (XRD) and polarized light microscopy (PLM), respectively. Eight blends of various ratios of ternary mixtures were investigated based on the previously studied binary fat mixtures. The composition of palmitic (P) and oleic (O), POP, and crystal morphology (size and shape) of the PMF/RBDPKO/RBDPS [14.9/59.6/25.5 (\%w/w)] mixture were comparable to cocoa butter (CB), while its melting profile $\left(18.5\right.$ and $\left.37{ }^{\circ} \mathrm{C}\right), \mathrm{SFC}$ at $20^{\circ} \mathrm{C}$ and polymorphism were different from $\mathrm{CB}$. The isosolid diagrams of the mixture displayed a monotectic effect at $20-25{ }^{\circ} \mathrm{C}$. Therefore, the 14.9/59.6/25.5 PMF/RBDPKO/RBDPS mixture could be used as a CBS in confectionery fillings because of the crystal morphology and monotectic behaviors comparable to those of CB.
\end{abstract}

Keyword: Ternary; Crystal; Cocoa butter; Iso-solid diagram; Polarize 